\title{
Las escuelas étnicas de la comunidad francesa. El caso argentino, 1880-1950\%
}

\author{
The ethnic schools of the French community. \\ The Argentine case, 1880-1950
}

\section{Hernán Gustavo Otero}

IEHS, Universidad N. del Centro de la Provincia de Buenos Aires, Tandil, Argentina

A partir de documentación diplomática inédita de Francia, el texto reconstruye las características y la evolución de las escuelas francesas de la Argentina durante el periodo 1880-1950. Para ello formula una definición analítica y operacional del concepto de escuelas étnicas e indaga las razones de la debilidad de las escuelas francesas, distinguiendo las vinculadas a la situación premigratoria (niveles de alfabetización y nacionalización de los emigrantes, políticas de Francia en Latinoamérica) y a la posmigratoria (evolución del sistema público de enseñanza de la Argentina, fractura de clase de la comunidad migratoria, expectativas de retorno, etc.).

PALABRAS Claves: Escuelas étnicas; Comunidad francesa; Argentina.

Based on unpublished French information, this text analyses the main characteristics and the historical evolution of French schools in Argentina between 1880 and 1950. It begins by establishing an analytical and operational definition of the concept of ethnic schools, and proceeds to study the causes of the weakness of these institutions, distinguishing between those related to pre-migratory conditions (such as levels of illiteracy and of adoption of French national identity by emigrants, French policies towards Latin America) and those taking place after migration (the evolution of the Argentine public education system, the class cleavage inside the immigrant community, the expectation of return-migration, etc.).

KEYwORDS: Ethnic schools; French Community; Argentina.

1 Agradezco los comentarios de Alicia Bernasconi, Carina Frid, Lucía Lionetti y de los árbitros anónimos. 


\section{Introducción}

Las escuelas étnicas constituyen un tema esencial de los estudios migratorios por su vinculación con, al menos, tres problemas: su relación con otros esfuerzos desplegados por las comunidades, en particular el movimiento asociativo; su papel como lugar de socialización de la segunda generación de inmigrantes mediante la incorporación de pautas culturales del país de origen; y su carácter de indicador de la integración migratoria en el clásico debate entre las teorías del Pluralismo Cultural y el Crisol de Razas. ${ }^{2}$ Partiendo de esta problemática general, el presente estudio busca subsanar la ausencia de trabajos sobre las escuelas francesas a partir del análisis de fuentes estadísticas y diplomáticas francesas no utilizadas hasta el presente. ${ }^{3}$

El primer problema consiste en recortar un objeto de análisis -las escuelas étnicas - que, como es habitual en los estudios migratorios, tiende a confundirse con aspectos más generales del país receptor como la presencia extranjera y la historia de la educación en la Argentina. Los educadores franceses ocuparon, en efecto, un lugar destacado en el colosal brain draim europeo que acompañó a la emigración de masas. El flujo de educadores estuvo compuesto por quienes contaban con calificaciones formales pero también por aquellos que, sin tener títulos específicos, desempeñaron ese papel en un país cuyo acelerado proceso de modernización demandaba un número creciente de educadores. A ello se sumó la francofilia cultural de las elites políticas e intelectuales nativas durante la segunda mitad del siglo XIX y la influencia que tuvo el sistema de enseñanza francés en la Argentina, visible en los contenidos, en la selección de textos obligatorios y en las orientaciones ideales de la escuela secundaria. La influencia de los educadores franceses en este país constituye, en suma, un tema amplio y heterogéneo debido a la pluralidad de situaciones que los tuvieron como protagonistas y que conviene distinguir analíticamente.

2 Los méritos y límites de ambas teorías son analizados en Devoto y Otero, 2003, pp. 181227. Una síntesis general de los debates sobre escuelas étnicas en Thernstrom, Orlov y Handlin, 1980, pp. 303-319. Los franceses fueron el tercer grupo migratorio hasta 1914, aunque con proporciones muy inferiores a italianos y españoles. La presencia gala pasó de 32.336 inmigrantes en el censo de 1869 a 94.098 en 1895 y declinó a 79.491 en 1914. Para un análisis del origen regional y de las causas de la emigración francesa a la Argentina, aspectos que exceden los límites del presente texto, ver Otero, 2005.

3 Aunque rica en hipótesis, la producción sobre escuelas étnicas en la Argentina es aún escasa y se refiere a daneses, judíos y, sobre todo, italianos. Las únicas excepciones para el caso francés son Lassalle et al., 1998, y de modo bastante más marginal, Sofer y Szchuman, 1975, pp. 334-359. 
Un primer grupo incluye a las figuras que actuaron en las instituciones públicas argentinas, abiertas por definición a todos sus habitantes y sin distinción de orígenes nacionales. Enumerar a la totalidad de los educadores galos que se desempeñaron en este rubro excede desde luego los fines de este trabajo; baste recordar, en cambio, a los principales referentes. Dejando de lado a quienes ingresaron al país durante la etapa rivadaviana, fuera de nuestro periodo de observación, se destacaron, en primer término, los educadores asociados a la experiencia de Justo José de Urquiza en la provincia de Entre Ríos, donde brillaron las figuras de Alberto Larroque (1819-1881), rector del Colegio de Concepción del Uruguay y hacia el final de su vida miembro del Consejo Nacional de Educación, y del polifacético exiliado republicano Alexis Peyret (1826-1902), quien dictó clases en esa institución y en la Universidad de Buenos Aires. En segundo término, el polo tucumano brilló con las figuras del también exiliado Amadée Jacques (1813-1865), docente del Colegio San Miguel entre 1858 y 1862, rector del Colegio Nacional de Buenos Aires y miembro de la Comisión del Plan de Instrucción General y Universitaria para la República Argentina, cuya redacción se le atribuye; y de Paul Groussac (1848-1929) quien, entre otros cargos, trabajó a partir de 1871 como profesor del Colegio Nacional de Tucumán durante más de diez años. ${ }^{4}$ Por último, en el caso porteño, debe mencionarse a Raúl Legout, docente del Colegio Modelo de Buenos Aires, director de la Escuela Superior Catedral al Sur, vicerrector del Colegio Nacional de Buenos Aires, subinspector de Escuelas de Provincias, profesor y rector del Colegio Nacional de Jujuy, inspector nacional de escuelas del Consejo Nacional de Educación y miembro del Congreso Pedagógico de 1882. A esas figuras, cuyas trayectorias vitales se asocian a múltiples puntos de la geografía nacional, debe agregarse un sinnúmero de educadores que desarrollaron su trabajo en el ámbito público por poseer títulos franceses habilitantes (profesores de escuelas normales, por ejemplo) o porque sus competencias técnicas, profesionales o linguísticas (el contar con el francés como lengua madre constituía un capital evidente para la enseñanza de ese idioma) los habilitaban para la docencia. Esta fue ejercida de modo permanente o como una ocupación refugio en momentos específicos del ciclo de vida, como lo evidencian las trayectorias de personajes tan dispares como

4 Para referencias biográficas de los educadores franceses en la educación pública argentina, ver Páez de la Torre, 1979, pp. 41-44, y De la Croix-Riche Chanet, 2004, pp. 728-749. El director de la Biblioteca Nacional, Paul Groussac, ha recibido mayor atención; ver sobre el particular la semblanza hecha por Clemenceau, 2002 [1911], pp. 57-60, y sobre todo Bruno, 2005. 
Charles Sourigues (1805-1870), agrimensor de la Colonia San José en Entre Ríos, el sabio Martín de Moussy (1810-1869) y el citado Paul Groussac. ${ }^{5}$

Un segundo grupo de educadores estuvo compuesto por miembros de las congregaciones religiosas de origen francés. La llegada al país de estas órdenes experimentó dos picos importantes: a partir de la década de 1880 y, con mayor intensidad, desde las leyes francesas de supresión de la enseñanza religiosa y de separación de la Iglesia y el Estado de 1905 (ley Émile Combes) que dieron lugar a la emigración de unos 30.000 congregacionistas. ${ }^{6}$ Entre las múltiples órdenes arribadas a la Argentina se destacaron los Padres Bayoneses, llegados en 1856 como respuesta a una invitación del obispo de Buenos Aires originada en la necesidad de asistencia espiritual a las familias vascas; dos años más tarde, el padre Diego Barbé fundó el Colegio San José, atendido luego por la Congregación del Sagrado Corazón de Jesús de Betharram. Otras fueron los Padres Lazaristas (llegados en 1859), los Misioneros de la Inmaculada Concepción de Lourdes o lourdistas, congregación fundada en Francia en 1848 y llegada a la Argentina en 1890, que creó, entre otros, los colegios de San Miguel en la capital y del Sagrado Corazón de Jesús en Tucumán; y los Hermanos Maristas de la Enseñanza (Champagnat) arribados en 1903. Entre 1854 y 1914, llegaron al país 28 órdenes y congregaciones religiosas de varones y 38 de mujeres, prevaleciendo las francesas entre las primeras en cuanto a docencia y las italianas en lo relativo a la acción misional.

La importancia educativa de estas congregaciones fue enorme, aunque poco estudiada hasta el momento, pero resulta menos clara su impronta étnica, la cual, sin embargo, no puede ser descartada a priori. Entre las razones para no hacerlo se encuentra el lugar de origen de estas instituciones, que tenía una evidente connotación étnica, tanto francesa, como regional, ya que la mayoría provenía de las mismas zonas del sur del Hexágono de las que eran oriundos los inmigrantes. Para aquellos recién llegados que profesaban el catolicismo, este se moduló basándose en referencias regionales y en ciudades emblemáticas de la religiosidad popular como Lourdes o Betharran. Asimismo, muchos inmigrantes priorizaron las escuelas de las congregaciones también por su origen nacional y no sólo por razones pura-

5 El propio Groussac señalaba esta situación al sostener en El Monitor de la Educación Común (17 de noviembre de 1882, p. 190) que «la enseñanza ha sido hasta ahora la playa más ó menos hospitalaria donde todos los náufragos de la existencia levantan su tienda de un día, su abrigo provisorio», citado por Bruno, 2009, p. 345.

6 Duclert y Prochasson, 2007, pp. 202-208. 
mente confesionales, aunque estas fueran en general compartidas, especialmente por aquellos que se oponían a las medidas laicas de la Tercera República. ${ }^{7}$ Las escuelas religiosas tuvieron asimismo un enorme rol en la difusión del idioma francés gracias a la presencia de sacerdotes-maestros de ese origen, y debieron desempeñar en tal sentido un papel análogo, aunque probablemente menos influyente que el ejercido por los salesianos en la preservación del idioma italiano. ${ }^{8}$ Su orientación confesional favoreció además la superación del sesgo de clase que, como veremos, caracterizaba a las escuelas laicas de la comunidad. Sin embargo, y a pesar de esas referencias, los colegios de las congregaciones impartían una educación en español de acuerdo con contenidos que, según los informes consulares y las encuestas sobre instituciones francesas realizadas por el Ministère des Affaires Étrangères en 1912, 1930 y 1950, ${ }^{9}$ eran acordes con las currículas oficiales argentinas y dieron prioridad a una línea educacional de corte confesional y no étnica. Más importante aún, se dirigían a un público plurinacional en el cual la mayoría de los alumnos eran argentinos, sin que la presencia francesa fuera en ellas destacable, salvo excepciones como los colegios religiosos de la colonia averyonesa de Pigüé fundada en $1884 .^{10}$ Por último, puede argumentarse que el hecho de que la población fuera en su mayoría católica contribuyó a que las escuelas religiosas francesas tuvieran en la Argentina un papel menos activo y militante de preservación étnico-religiosa que las comunidades francesas instaladas en países con predominio protestante, como los Estados Unidos, o con un sustrato francófono que debía ser preservado, como en Canadá, ${ }^{11}$ y que las comunida-

7 Ese era el caso, por ejemplo, de muchos católicos aveyroneses instalados en Pigüé. Véase Andreu et al., 1977, p. 258. No hay que olvidar que el Vaticano condenó en 1875 la frecuentación de escuelas públicas y que ello debió influir en los sectores católicos más militantes de las comunidades.

8 Rósoli, 2000, pp. 237-260. Sobre italianos ver también los trabajos de Frid de Silberstein, 1985 y 1992; y Favero, 1985.

9 Statistique Générale de la France (en adelante SGF), 1915 y 1935; Institut National de la Statistique et des Etudes Économiques, 1955 (de aquí en adelante Encuestas del MAE).

10 Las escuelas de las congregaciones francesas son analizadas por el jesuita Lhande, quien discute la tesis de la supuesta indiferencia religiosa de los emigrantes vascos en el nuevo mundo y, de manera más dispersa, por otros autores. Ver Lhande, 1984 [1910] y Dussaut, 1966. Estudios más sistemáticos son los de González, 1979, pp. 89-122, y Auza, 2005.

11 El caso canadiense tuvo dos especificidades notables: el papel del clero como agente de encuadramiento del flujo migratorio y la coexistencia de comunidades francófonas de diferente origen. El cierre de las escuelas católicas en Francia en 1903 originó la emigración de unos 2.000 religiosos al Canadá entre 1900 y 1914, que buscaron recrear allí comunidades católicas basadas en las colonias de emigrantes. Por ello, la Iglesia tuvo allí una defensa militante de la francofonía y de una específica versión del catolicismo (la ideología de la survivance no exenta de nacionalismo) muy diferente al caso argentino. Ver Quintal, 1990; y Frenette, 2002. 
des no católicas de Argentina, fueran de confesión protestante (británicos, alemanes y daneses) o judía.

Una tercera categoría remite a la Alianza Francesa, fundada en París el 21 de julio de 1883, que contó con una filial en Buenos Aires a partir de 1893. Al igual que la Dante Alighieri o el Instituto Goethe, su objetivo fue el de difundir la lengua y la cultura del país de origen a la población en general y no sólo a los descendientes franceses. La sede porteña fue fundada por el doctor François Simon, junto a personalidades y empresarios franceses y argentinos, y tuvo como primer presidente a Alexis Peyret. En una primera fase estimuló la enseñanza del francés en los colegios de la capital; a partir de 1896 preparó exámenes, para luego dar cursos y transformarse progresivamente en una verdadera escuela de idioma, lo que convirtió a la red de Argentina en la más importante del mundo hacia fines de la década de 1920. La Alianza tuvo un gran desarrollo entre 1910 y 1930 e inició luego una «fase de decadencia o de esclerosis paralela al debilitamiento de la colonia francesa». La situación comenzó a revertirse en la inmediata posguerra gracias al Comité pour le Rayonnement Français que sacó a la institución de su aislamiento y logró aumentar el número de alumnos y de filiales en todo el país. ${ }^{12}$ La encuesta del Ministère des Affaires Étrangères de 1950 dio cuenta de la existencia de 53 filiales agrupadas en una Federación con un total de 10.000 alumnos. Esta encuesta, que a diferencia de las anteriores permite conocer la nacionalidad de los adherentes a la institución, muestra que apenas el $10 \%$ de los mismos eran por ese entonces franceses, aunque la proporción fuera más alta en lugares emblemáticos de colonización gala como San Rafael (43\%), en la provincia de Mendoza, y Pigüé (97 \%), en la de Buenos Aires. ${ }^{13}$ Dentro de este grupo se pueden incluir también los esfuerzos del Estado francés en el ámbito de la educación superior como la creación del Instituto Francés de Estudios Superiores en 1942, destinado al público en general. ${ }^{14}$

Un cuarto grupo fue el de las escuelas privadas no confesionales, objeto central del presente texto, pero que no siempre tuvieron un carácter étnico

12 Archives du Ministère des Affaires Étrangères (en adelante AMAE), Note sur la colonie française d'Argentine, Buenos Aires, 21 de octubre de 1949, Roger Monmayou au MAE, pp. 208-237, p. 223.

13 Elaboración propia en base a los casos de filiales con datos completos, Encuesta del MAE de 1950, pp. 356-357.

14 El Instituto fue fundado por Robert Weibel-Richard y Roger Callois. Según la encuesta del MAE de 1950, p. 57, tenía 1.000 alumnos y contaba con el patronato científico de las Universidades de Paris y Bordeaux. 
evidente. Por citar un ejemplo, las instituciones fundadas por Adolphe Soulié y Madame Soulié en La Plata (la École Saint-Louis y la Institution Nôtre Dame para señoritas), a pesar de sus nombres, captaron a un público muy amplio en el que predominaban los hijos de las familias argentinas de alto poder adquisitivo de la ciudad y de su zona de influencia. ${ }^{15}$ Estos casos no eran la excepción ya que muchas escuelas con nombres y directores franceses estaban destinadas a un público heterogéneo y, como lo muestran sus avisos, ostentaban su origen francés como elemento de propaganda en virtud del prestigio con que eran miradas por la sociedad argentina.

En este grupo se incluyen las escuelas primarias y secundarias de carácter étnico, cuya definición, a los fines del presente estudio, incluye cuatro aspectos esenciales: a) surgieron de iniciativas de actores comunitarios locales (lo que deja de lado a las escuelas religiosas); b) se orientaban a la preservación de la cultura francesa; c) recibían subsidios del país de origen; y d) contaban con una proporción significativa de alumnos oriundos de Francia o de padres franceses. La coexistencia de estos rasgos es de vital importancia para el mantenimiento y la reproducción de la comunidad migratoria ya que remite al decisivo aspecto de la socialización de los hijos de inmigrantes en la cultura de la nación de origen.

$\mathrm{Al}$ igual que en el asociacionismo, con el que el tema tiene estrecha vinculación en la medida en que ambos constituyen piezas centrales del entramado comunitario, el estudio de las escuelas étnicas afronta los riesgos de subestimar o sobrestimar la real importancia del fenómeno. La ausencia de análisis basados en modelos endógenos, es decir consagrados al funcionamiento interno de las instituciones educativas, y los límites de las fuentes actúan en el mismo sentido. ${ }^{16}$ Con todo, el riesgo de sobrestimación de la impronta étnica de las instituciones es, en principio, el más evidente ya que buena parte del esfuerzo educativo realizado por instituciones total o parcialmente «francesas» no siempre tuvo los rasgos étnicos definidos precedentemente, razón por la cual el relevamiento que aquí se propone tiene un sesgo alcista.

15 Sobre Madame Soulié y algunas escuelas «francesas» de La Plata, ver el bello texto de Lassalle et al., 1998. Su trayectoria personal (institutriz en familias ricas como los Sánchez Sorondo, maestra de escuelas privadas y de escuelas públicas, miembro del núcleo fundador del Colegio Nacional de Santa Rosa, La Pampa) es ilustrativa de las múltiples posibilidades de inserción y de movilidad social de los educadores extranjeros.

16 El estudio endógeno permitiría conocer las formas de reclutamiento de los docentes y del personal directivo, los montos de las cuotas, lor requisitos de admisión de los alumnos, los programas, contenidos, recursos didácticos y valores transmitidos, las características de los edificios, etc. Lamentablemente, las fuentes necesarias para este tipo de estudio son inexistentes en el caso francés. 


\section{Las escuelas étnicas: características y evoluciones}

Si centramos nuestra mirada en las escuelas primarias y secundarias no confesionales susceptibles de ser caracterizadas como étnicas, la imagen que emerge con toda claridad es su menor presencia y desarrollo en relación a otros esfuerzos de la comunidad como el asociacionismo en sus múltiples formas (sociedades de protección a los inmigrantes, de beneficencia, de socorros mutuos, recreativas, deportivas, culturales y regionales). ${ }^{17}$

Las primeras referencias consistentes sobre el particular datan de la década de 1880, momento en el que Émile Daireaux (1843-1916), abogado francés y referente de la comunidad por su tarea periodística en L'Union Française y Le Courrier de La Plata, menciona la existencia de «escuelas numerosas» cuyo carácter étnico no era evidente ya que «se contentan de ser universitarias, a la moda del país, y de preparar a los niños a los exámenes que el Estado exige a cada grado de la enseñanza primaria, secundaria o superior». ${ }^{18} \mathrm{Al}$ igual que las sociedades de socorros mutuos, los emprendimientos más importantes estaban en las principales urbes del Litoral y sobre todo en la ciudad de Buenos Aires. Allí fueron creados el Colegio Rollin (1878) y el Carlomagno (1880). En torno al cambio de siglo surgieron los colegios Central, Francés y Pueyrredón. Otras fundaciones de la capital fueron el Orfanato Francés, dirigido por las Damas de la Providencia (con más de 60 alumnos); San Carlos, escuela francesa mixta; y el Colegio Victor Hugo (1887) que, según su publicidad, daba clases en francés, pero también en castellano, inglés, italiano, griego, etc. El carácter étnico de este colegio resulta más claro si se considera que fue colocado a principios del siglo XX bajo el patronato de la Legación de Francia en Buenos Aires y que en 1908 recibió subsidio del gobierno francés. ${ }^{19}$

Fuera de la capital se destacaban el Colegio Richelieu de La Plata, cuyo director, Rodenet, demandó en 1888 libros y mapas al Ministerio

17 Sobre el particular ver Otero, en prensa.

18 Daireaux, 1889 , p. 36. Por su parte, la información consular, que tiene un alto subregistro probablemente por incluir sólo a los franceses matriculados en los Consulados, consigna que para 1885 había en la capital 1.530 alumnos franceses que «frecuentaban las escuelas públicas o particulares», AMAE, Affaires Diverses Politiques (en adelante ADP), 1815-1896, Tomo II.

19 En 1908 el colegio Victor Hugo recibió una subvención de 400 francos del MAE. Esas ayudas no eran regulares ya que en 1902 se insistía desde París sobre la imposibilidad de otorgarle una subvención anual. Centre des Archives Diplomatiques de Nantes (en adelante CADN), College Victor Hugo, Carton 68. Para mayor coherencia, los nombres de las instituciones que aparecen en el texto han sido castellanizados. 
de Instrucción Pública de Francia, ${ }^{20}$ y el Colegio Francés de Córdoba. A mediados de la década siguiente se crearon en Tucumán el Colegio Carlomagno (1894), que hasta 1897 fue de enseñanza primaria exclusiva para varones, y el Colegio Francés (1895), que daba clases en francés y castellano y comprendía un curso superior de niñas con una sección especial de labores. A ellos deben sumarse la Escuela Francesa de Santa Fe, perteneciente - según la encuesta de 1912 - a una sociedad de franceses, suizos y belgas, y la Escuela Francesa de Rosario. ${ }^{21}$ También había centros educativos en otras ciudades de la provincia de Buenos Aires donde la presencia francesa era significativa, como Bahía Blanca, Chascomús, Coronel Pringles, Piguié, etc. El último caso resulta nuevamente emblemático ya que contaba con al menos cuatro establecimientos de origen francés hacia 1913.

La distribución geográfica observada ratifica que los principales emprendimientos fueron realizados, al igual que en las asociaciones, en las grandes urbes como Buenos Aires, Rosario, Santa Fe, Córdoba y Tucumán y en enclaves de colonización francesa como Pigüé. Las ciudades intermedias, en cambio, no se destacaron en este plano, como lo ilustra el caso de Tandil, núcleo urbano representativo de la provincia de Buenos Aires que nunca tuvo una escuela francesa pero sí una mutual bastante activa desde 1894 (la Sadi Carnot). Todo indica en suma que en ese tipo de espacios el socorro mutuo era una necesidad sentida por las comunidades pero que no ocurría lo mismo en el plano educativo. ${ }^{22}$

Las escuelas étnicas fueron más importantes en las colonias rurales que contaban con una proporción significativa de franceses o, en términos más generales, francoparlantes, lo que permitía la inclusión en los establecimientos de belgas y de suizos de lengua francesa. El carácter fundacional de esos espacios, en los que todo estaba por hacerse, se verifica claramente en los proyectos de fundación de las colonias que, además del Concejo Municipal o de organismos análogos, preveían entre sus primeras medidas la creación de una escuela. De modo emblemático, el

20 AMAE, Renseignements sur la population scolaire française, 1886, ADP, Carton 2, 18151896, Tomo II.

21 La información disponible para 1918 da una lista algo diferente de los principales colegios: «La Salle, Lacordaire, Saint Joseph, Pueyrredon, Sadi Carnot, Charlemagne, l'Enfant de Jesus, Fenelon, Rollin», y aclara que «de todos modos en ellos la enseñanza en español es obligatoria», CADN, Cuestionnaire au cónsul de France à Buenos Aires Mr. Gaussen, 18 de noviembre de 1918, Carton 105.

22 Otero, 2005, pp. 107-115. 
primer contingente arribado a la colonia de Pigüé contó entre sus miembros a la maestra Julie Bras, egresada de la Escuela Normal de Rodez (Aveyron). La creación de la primera escuela francesa de Pigüé, en la que daba sus cursos Bras utilizando la lengua francesa, reforzó la cohesión social y étnica del grupo colonizador inicial. Sin embargo, no todos los descendientes de franceses de la colonia iban a esa escuela, ${ }^{23}$ a lo que se suma que - tarde o temprano, pero en general muy pronto- el Estado argentino impuso en esos espacios la educación pública. Así, desde 1893 (apenas nueve años después de la fundación de la colonia), Pigüé contó con una escuela primaria del Estado provincial, cuya enseñanza era impartida en español, a la que se agregó una segunda en 1908. Con ligeras variantes, lo mismo ocurrió en otras colonias donde la presencia francesa era importante. En la de San José (Entre Ríos), por ejemplo, «se enseñó en francés durante más de cuatro años, hasta que el gobierno provincial nombró maestros oficiales, pasando a hacerse súbitamente en castellano a pesar del pedido de la comuna, en 1862, para que la educación fuera bilingüe». ${ }^{24}$

Visto el problema en clave diacrónica, el auge de las escuelas francesas ocurrió, al igual que en las asociaciones, hacia el Centenario de la Revolución de Mayo. Si bien el Censo de Sociedades Mutuales de 1913, editado como parte del III Censo Nacional del año siguiente, sólo da cuenta de tres escuelas francesas dependientes de asociaciones de ese origen (Minerve, 1879, en la Capital Federal; la Sociedad Francesa de Tucumán, 1893; y la Mutuelle Mabilleau, 1912, de Resistencia, Chaco), esa cifra se halla claramente subestimada, en buena medida porque refleja únicamente el esfuerzo educativo de las mutuales. ${ }^{25}$ La encuesta del MAE de 1913, en cambio, resulta mucho más precisa ya que menciona 16 instituciones educativas, reflejadas en el Cuadro 1.

23 No todos los franceses enviaron sus hijos a esa escuela, como lo evidencia el caso de la familia Champredonde, en Roberto Champredonde: «Los Champredonde en Argentina», mimeo, 2002, p. 17. Por otra parte, los hijos de franceses pobres no concurrían a ningún tipo de establecimiento, como lo muestra el bello diario de la inmigrante Anaïs Vialá en Di Liscia y Lassalle, 2002.

24 Guionet, 2005, p. 132.

25 Las sociedades mutuales extranjeras no ejercieron gran influencia en este rubro, ya que de las 214 asociaciones censadas en la capital argentina en 1913 solo 21 contaban con escuelas. Estas cifras son cuestionables ya que se refieren únicamente a las escuelas dependientes de mutuales. Los propios censistas consideraban que la información no era confiable ya que detectaron 29 escuelas italianas pero «según informaciones de fuente particular, hemos sabido que son más de cincuenta», «Sociedades de socorros mutuos. 1913», en Borea, 1917, p. 96. 


\section{CuAdro 1}

INSTITUCIONES EDUCATIVAS FRANCESAS EN LA ARGENTINA, FINES DE 1912

Institución Año de fundación Total de alumnos $\begin{gathered}\% \text { de alumnos con } \\ \text { padres franceses }\end{gathered}$

\section{Capital Federal}

Colegio Central

Colegio Carlomagno

Colegio Francés

Colegio Pueyrredón

Colegio Rollin

Colegio Victor Hugo

Institución Francesa

$\begin{array}{rrr}1897 & 120 & 22 \\ 1880 & 230 & 0 \\ 1904 & 48 & 56 \\ 1904 & 533 & 4 \\ 1878 & 154 & 31 \\ 1886 & 300 & 28 \\ 1883 & 72 & 39\end{array}$

\section{Provincia de Buenos Aires}

Colegio Rivadavia (Bahía Blanca)

Colegio Comercial (Chascomús)

Colegio del Niño Jesús (Pigüé)

Colegio Carlomagno (Pigüé)

Colegio de las Naciones (Pigüé)

Escuela Sagrada Familia (Pigüé)

Colegio Francés (Coronel Pringles)

1911

1897

1888

1900

1909

1905

1898

22

56

\section{4}

31

28

39

Provincia de Santa Fe

\begin{tabular}{lrrr} 
Escuela de la Alianza Francesa (Rosario) & 1912 & 356 & 9 \\
Escuela Francesa de Santa Fe (Santa Fe) & 1900 & 106 & 68 \\
\hline Total & & 2716 & 22
\end{tabular}

Fuente: elaboración propia en base a Encuesta del MAE, 1913, p. 182. La última columna expresa el porcentaje de alumnos con padres franceses en el total de alumnos de cada establecimiento.

Con la excepción de las más evidentes, como el Colegio Victor Hugo y la Escuela Francesa de Santa Fe que «recibían débiles subvenciones del gobierno francés», ${ }^{26}$ la información disponible no permite precisar el carácter étnico de muchas de ellas, pero el dato relativo a la asistencia de alumnos «hijos de padres franceses», crucial en nuestra definición de escuelas étnicas, posibilita un acercamiento sugerente. Según la encuesta, «los hijos de franceses no forman más que una pequeña fracción [de los establecimientos de enseñanza], los hijos nativos son mucho más numero-

26 AMAE, Service des Oeuvres Françaises à l'Étranger, Buenos Aires, 25 de junio 1920, Carpeta Amérique, 1918-1940, Argentine (14), Propagande, 1914-1921, p. 133. 
Sos». ${ }^{27}$ Sin embargo, el Cuadro admite una lectura más matizada ya que el Centenario muestra tanto un grado importante de Pluralismo Cultural - es decir una proporción no desdeñable de alumnos de origen francés en escuelas que por tal razón pueden considerarse étnicas - ${ }^{28}$ como el hecho de que la mayoría de los estudiantes no pertenecían a esa nacionalidad y de que existía, por tanto, una suerte de crisol al interior de los mismos colegios. El promedio general (22\% de alumnos de padres franceses en las 16 instituciones) esconde asimismo casos donde la presencia francesa era superior al 50\% (como el Colegio Francés de Buenos Aires, el del Niño Jesús y el Colegio de las Naciones, ambos de Pigüé, y la Escuela Francesa de Santa Fe), que repiten los hallazgos pluralistas obtenidos sobre el movimiento asociativo. El cuadro permite también otra lectura más general: si se tiene en cuenta la población escolar potencial de alumnos con al menos un progenitor francés de cada jurisdicción, la proporción de personas de ese origen que iban a las escuelas étnicas resulta insignificante.

Lamentablemente, la ausencia de datos en las encuestas siguientes no permite un análisis semejante para 1930 y $1950 .{ }^{29}$ Con todo, sus redactores consideraban que en la Argentina, al igual que en otras partes del mundo, se asistía entonces a una tendencia paradógica: el aumento del número de escuelas y de alumnos a pesar de la reducción de los tamaños de las comunidades ocurrida tras la Gran Guerra. Un signo, y acaso también un factor, de ese dinamismo es suministrado por las subvenciones del gobierno francés, que se hicieron más amplias (en relación a la cobertura de instituciones, no necesariamente en las sumas recibidas) en la década del veinte como parte de los planes de propaganda francesa de la primera posguerra que corresponden a lo que Pelossi ha definido acertadamente como el «mesianismo cultural francés». ${ }^{30}$

27 Encuesta de 1912, pp. 159-160. Otros establecimientos del siglo XX fueron el Pasteur, el Colegio Francés de Monsieur Crespin, AMAE, Note sur la colonie française....

28 El razonamiento se basa en el concepto de núcleo étnico (Otero, en prensa), definido como la proporción de personas que, dentro de un agregado estadístico indiferenciado (por ejemplo la «población francesa»), forma parte de la comunidad migratoria. El concepto permite una medición complementaria y comparativa con otros indicadores estadísticos de la integración migratoria como la exogamia y la segregación espacial. El núcleo étnico obtenido sería probablemente mayor si se pudiera contar con la nacionalidad de los abuelos de los alumnos.

29 La encuesta de 1930 menciona cuarenta establecimientos franceses sin diferenciar laicos y religiosos, aunque estos últimos constituyen una mayoría evidente, con un total de 10.000 alumnos; doce de ellos estaban en Buenos Aires, siete en Rosario, cuatro en Pigüé y cuatro en Santa Fe.

30 Pelosi, 1999. Hacia fines de la década de 1910 las subvenciones se distribuían del siguiente modo: Alianza Francesa de Buenos Aires, 7.750 francos; Colegio Victor Hugo, 1.000; escuelas francesas de Santa Fe y de Tucumán, 1.500; compra de libros en Buenos Aires, 1000, AMAE, Subventions 
A las instituciones subsidiadas se sumaron entonces la Alianza Francesa de Buenos Aires y la Escuela Francesa de Tucumán, cuya piedra fundamental había sido colocada por Georges Clemenceau en su visita de 1910. La ayuda del Estado de origen era completada en muchos casos, como el Colegio Francés de Buenos Aires, con el apoyo económico de miembros francófilos de la elite argentina. ${ }^{31}$ Esas ayudas sugieren asimismo que, al igual que las sociedades de socorros mutuos, las escuelas atravesaban dificultades financieras crecientes, a lo que no debió ser ajena la fragmentación de la oferta educativa en un contexto de fuerte reducción de los flujos y del tamaño de la comunidad francesa de la Argentina.

La decadencia de las escuelas étnicas comenzó a ser evidente a partir de la década de 1930 como lo sugieren, entre otros registros, las respuestas del Comité de Sociedades Francesas de Buenos Aires al cuestionario destinado a la elaboración de las propuestas para el V Congreso de Franceses en el Extranjero. En un extenso documento, Jean-Pierre Passicot, presidente del citado Comité, informaba que las preguntas hechas tenían «un interés muy relativo» ya que

los diversos colegios franceses que existían en el pasado en Argentina han desaparecido uno tras otro, por la imposición de enseñar unicamente en español, y de seguir exactamente los programas de enseñanza del país, que difieren muy sensiblemente de los de Francia. Fuera de los establecimientos congregacionistas que en razón de las dificultades de reclutamiento de personal docente francés, como consecuencia de la supresión de los noviciados, no pueden acordar a la enseñanza del francés el lugar que ocupaba antes en sus programas, no hay en Buenos Aires más que dos colegios franceses administrados por particulares, uno de importancia relativa, el otro de menor importancia aún. Los niños enviados a Francia, sea de colegios congregacionistas, sea de colegios laicos, se encontrarían desorientados por la diferencia de los programas.

\footnotetext{
de propagande accordées sur le chapitre J aux postes diplomatiques et consulaires en Amérique, 17 de mayo 1921, Correspondance Politique et Comerciale (CPC), 1914-1940, Série B: Amérique, Dossiers Généreaux, Carton 206. A fines de la década siguiente, el embajador insistía en la necesidad de mantener «las subvenciones relativamente modestas que solicito» y que las mismas «sean integralmente acordadas, fueran cuáles fueran las dificultades financieras de la hora actual». Argumentaba asimismo que la gran mayoría del crédito pedido se aplicaba a «obras de propaganda intelectual que no podríamos dejar periclitar sin atacar, al mismo tiempo, y de manera grave, la influencia francesa aquí», AMAE, Subventions aux oeuvres françaises pour 1927 sollicittées par l'Ambassadeur Georges Picot, Buenos Aires, 21 de febrero de 1929, Série B: Amérique, Argentine: (16) Propagande, 1923-1929, pp. 122-124, 144-146.

31 Véase «Sejour en France de ancien Ministre de l'Agriculture de la République Argentine», que fue garante financiero de la creación del Colegio Francés de la capital. AMAE, Buenos Aires, 17 de enero 1936, Amérique 1918-1940, Argentine (86).
} 
Coherente con ese diagnóstico, Passicot se mostraba favorable al «envío de niños a estudiar a Francia», sobre todo de hijos de franceses que no estuvieran instalados definitivamente en el país, «lo que ayudaría a conservar en esos niños un espíritu francés que pierden casi siempre aquí por la frecuentación de sus camaradas de la escuela argentina, devienen más argentinos que estos últimos y se glorifican de ello»..$^{32}$ Los informes de las dos décadas posteriores repiten ese diagnóstico incluso para el emblemático bastión de Pigüé. Resulta interesante contrastar a este respecto las críticas de sectores de la sociedad argentina que demandaban una mayor presencia de la educación estatal con la visión de los líderes comunitarios y los agentes consulares que, por el contrario, la consideraban particularmente exitosa.

Hacia 1950 la decadencia era palpable en los colegios laicos ${ }^{33}$ pero también en los congregacionistas. A pesar de que la mayoría de estos últimos continuaba teniendo su institución madre en Francia, la encuesta de 1950 señala que «un gran número de los aproximadamente 250 establecimientos religiosos pertenecientes a más de 30 congregaciones [...] no puede ser considerado como francés en el sentido estricto del término». ${ }^{34}$ La mayoría de los directores eran entonces nativos y la educación ofrecida conforme a los programas argentinos, sin lugar especial para el idioma francés, cuya enseñanza devino facultativa en las escuelas secundarias a partir de 1941. Desde la década del treinta, los colegios religiosos se enfrentaban asimismo a considerables problemas de reclutamiento, provocados por la disminución de la llegada de religiosos y por el envejecimiento y «argentinización» (sic) de los sacerdotes existentes en el país. Ese panorama se agravó hacia fines de la década del cuarenta, momento a partir del cual los profesores debían «ser obligatoriamente argentinos y con diplomas argentinos, razón por la cual los franceses no juegan ningún rol».35

32 AMAE, Réponses du Comité des Societes Françaises de Buenos Aires, F. Lecroq (secretario), J. Passicot (presidente), Série B Amérique, Argentine: (17), Propagande, 1930-1937, pp. 30-41.

33 Para 1950, el Colegio Pasteur de Buenos Aires seguía los programas oficiales argentinos, con solo una hora de francés por día y tenía una «acción limitada»; la Escuela Francesa de Santa Fe, por su parte, ligada a la Compañía Francesa de Ferrocarril, se hallaba también en dificultades por «la compra de la compañía por el estado argentino y la partida de numerosas familias [que] hacen prever un debilitamiento de la escuela que ha sido incorporada a la Alianza Francesa», AMAE, Note sur la colonie... p. 223.

34 Encuesta del MAE, 1950, p. 58.

35 AMAE, Note sur la colonie..., p. 225; AMAE, (43), Établissements religieux français (1945-1951), Serie B Amérique, 1944-1952. 
La debilidad del tejido escolar comunitario tuvo asimismo evidentes efectos en la rápida adaptación lingüística de los inmigrantes, hecho destacado por todos los observadores contemporáneos sobre el que no podemos detenernos aquí. De modo consecuente, el desconocimiento del francés coadyuvó, junto a otros factores, a la pérdida de identidad de la segunda generación, como lo puso de manifiesto la respuesta de los argentinos hijos de franceses a la movilización militar de la Gran Guerra en 1914, prácticamente insignificante en relación a la de la primera generación de inmigrantes. ${ }^{36}$

\section{Los límites de las escuelas comunitarias: razones y conjeturas}

La menor presencia del tejido escolar francés genera numerosos interrogantes, tanto más porque contrasta con la notable capacidad asociativa de este colectivo. Una prueba adicional en tal sentido la suministra el hecho de que las escuelas nunca dieron lugar a organismos de segundo grado, como ocurrió con el movimiento asociativo (creación del Comité de Sociedades Francesas de Buenos Aires en 1902 y de la Federación de Mutualidades Francesas de la Argentina en 1913) y con las escuelas de la comunidad judía, que se nuclearon en un Consejo de Educación en 1935. ${ }^{37}$ Diversos son los factores que permiten arribar a una explicación de conjunto.

El primer factor decisivo fue el progresivo desarrollo del sistema estatal de educación a partir del Primer Congreso Pedagógico Argentino (1882) y de la sanción de la Ley de Educación Primaria de 1884 que, en sintonía con el espíritu laico y positivista de la Generación del Ochenta, estableció la enseñanza pública, obligatoria, gratuita y laica. La ley definió asimismo un modelo de integración republicana, de clara inspiración francesa, que hizo de la escuela un instrumento unificador al servicio de la nación, necesidad sin duda imperiosa en la heterogénea población argentina nacida de la preexistencia de comunidades indígenas y del aluvión migratorio. Además de esta filiación ideológica, cabe destacar la cuasi simultaneidad de las discu-

36 Un ejemplo, entre muchos, proveniente de un agregado militar francés: «...los padres hablan español incluso cuando son ambos franceses, hay pocas escuelas y su organización parece defectuosa sobre todo en lo relativo al reclutamiento de profesores», CADN, Capitain Salats, Buenos Aires, rapport del 29 de mayo de 1915, Carton 104. La misma opinión tenían autores contemporáneos como Clemenceau, 2002 [1911]; Papillaud, 1909; Serret, 1915. Los efectos de la movilización militar de 1914-1918 son analizados en Otero, 2009.

37 Zadoff, 1994. 
siones argentinas y francesas ya que la Ley 1420 fue sancionada sólo tres años después de la ley francesa del 16 de junio de 1881 que promulgó la gratuidad escolar, y apenas dos años más tarde que la ley del 28 de marzo de 1882 que estableció la enseñanza primaria obligatoria y laica. ${ }^{38}$

Este marco general definió un contexto de integración republicana a través de la educación pública que desembocó, de modo bastante natural dadas las premisas de base, en una fuerte desconfianza hacia las instancias de socialización que pudieran desafiar el monopolio estatal en la enseñanza primaria y secundaria. Ello implicó crecientes instancias de control y de competencia del sistema público frente a las opciones alternativas existentes: las escuelas religiosas, en su gran mayoría católicas, y las escuelas de las comunidades migratorias, dos frentes de lucha que, gracias a la acción de las congregaciones emigradas, tenían también puentes entre sí. ${ }^{39}$

La creación de organismos altamente centralizados como el Consejo Nacional de Educación en 1880 y la sanción de la Ley 1420 favorecieron el acelerado proceso de creación de escuelas públicas y el control del funcionamiento de las escuelas étnicas. A partir de 1888 se pusieron en marcha programas educativos de alcance nacional orientados, al igual que en el modelo francés, por la clara finalidad política de transformar a la escuela en agente activo de la nacionalidad argentina en construcción. Otros hitos de esa evolución fueron la exigencia a los maestros extranjeros de revalidar sus títulos en las escuelas normales del país (1889); el proyecto de ley de Nicolás Avellaneda sobre el uso exclusivo de la lengua nacional en todas las escuelas primarias (1896); el plan de enseñanza secundaria del

38 A pesar de ello, y dada la no separación entre Iglesia y Estado que caracteriza al caso argentino, la «neutralidad de la escuela desde el punto de vista confesional», en las célebres palabras de Jules Ferry, tuvo mayores retrocesos en la Argentina (por ejemplo, la influencia de contenidos moralizadores de inspiración religiosa en asignaturas como instrucción moral y cívica o la restauración de la enseñanza religiosa en las escuelas llevada a cabo por Perón en 1943) que en Francia. Sobre el proceso de construcción histórica de la laicidad y el rol patriótico asignado a la escuela pública en este último país durante la Tercera República, ver Baubérot, 2000.

39 Las críticas a las escuelas comunitarias comenzaron en 1881 con los artículos de Domingo F. Sarmiento en el diario El Nacional contra las escuelas italianas y se intensificaron a fines de esa década. El argumento central era que las escuelas comunitarias se habían convertido en instrumentos de formación de la nacionalidad italiana, lo que podía alimentar las ambiciones coloniales de ese país. Las difíciles relaciones entre las escuelas étnicas y el gobierno argentino y los mecanismos puestos en práctica por este último para la construcción de la nacionalidad argentina (escuela pública, proyectos de naturalización de los inmigrantes, creación de símbolos y de una liturgia patriótica, etc.) son analizados en el importante libro de Bertoni, 2001. La autora insiste en la influencia que habría tenido el el modelo prusiano para la emergencia — a partir de 1880 — de una concepción cultural y esencialista de la nacionalidad argentina, pero pasa por alto la importancia del modelo francés en el plano educativo. Sobre la evolución de la educación en Argentina ver asimismo Spalding, 1972, y Puiggrós, 1990-1991. 
presidente Roca en 1901 que, al igual que los precedentes, prescindía de la enseñanza religiosa en la escuela secundaria; la ley Láinez (1905), que estipuló que la Nación — por intermedio del Consejo Nacional de Educación - podía instalar escuelas primarias en las provincias que así lo solicitaran (ya que hasta entonces el federalismo de la Constitución limitaba la ley de educación común 1420 al ámbito de la Nación) y la ley de 1917, que impuso la obligatoriedad de maestros argentinos para permitir el funcionamiento de escuelas étnicas, exigencia que en la práctica venía siendo planteada desde antes por el Consejo Nacional de Educación. Este conjunto de medidas generales, más otras en igual sentido sancionadas por las legislaturas provinciales, dieron carnadura progresiva a las disposiciones de la ley de 1884, si bien su implementación total constituyó un proceso largo y complejo que se extendió, cuanto menos, hasta la década de $1940{ }^{40}$ La extensión del sistema público de enseñanza — tanto en su capilaridad institucional como en su modelo de integración de inspiración francesa- era, por otra parte, un rasgo argentino del que los diplomáticos franceses dieron cuenta en repetidas ocasiones. Así, por ejemplo, en 1899, en momentos de auge del flujo migratorio francés, el cónsul de Rosario envió una carta al Ministerio de tutela en la que emitía su opinión negativa sobre la creación una escuela francesa subvencionada promovida por $\mathrm{Mr}$. Courau, director de la Compañía Francesa de Ferrocarriles de Santa Fe. Más allá de que esa institución fue creada al año siguiente, el cónsul fundamentaba su opinión en que «sería mejor invertir en el imperio colonial», y que otras creaciones («una guardería, una biblioteca pagada por el director de la compañía de ferrocarriles, un atelier de aprendices») le parecían más urgentes y relevantes. Pero sobre todo sostenía que «dada la cantidad de gente de la colonia esa escuela sería inútil» y que ese colegio «no tendría nada de francés ya que la enseñanza sólo puede ser dada en base a los programas del Ministerio de la Instrucción Pública de la provincia [y que] las escuelas primarias y normales, secundarias y superiores del gobierno provincial son todas gratuitas y suficientes para las necesidades de la población». ${ }^{41}$ Con ligeras variantes, las razones esgrimidas por el cónsul (en esencia, la necesidad de invertir en otras áreas del imperio francés y la

40 La escuela pública convivió en efecto con instituciones particulares que la asistieron y completaron, entre ellas las religiosas, pero también otras como las redes educativas de las Damas de la Beneficencia. Ello permite matizar, aunque no invalidar, las interpretaciones tradicionales que veían al sistema público como altamente centralizado y eficiente en su capacidad de imposición ideológica.

41 AMAE, Projet de fondation d'une école française subventionnée, 19 de septiembre de 1899, Correspondance Commerciale et consulaire (CCC), Santa Fe, 1896-1900. 
inconveniencia de apoyar proyectos que no podrían competir con la educación pública argentina) serán una constante de la política francesa en la Argemtina durante las décadas siguientes..$^{42}$ Este tipo de consideraciones podría explicar asimismo la ausencia de críticas de las leaderships comunitarias francesas a la política educativa del Estado argentino, ampliamente documentadas en cambio para el caso italiano. ${ }^{43}$

Más allá de las consideraciones ideológicas inherentes al cargo (muy claras en lo relativo a la prioridad otorgada al imperio colonial), las interpretaciones consulares se basaban en los hechos ya que la proporción de analfabetos entre la población de 14 años y más pasó de 64,6 y 78,1\% en 1869 a 12,1 y $15,2 \%$ en 1947, para varones y mujeres respectivamente. A pesar de esos avances, no debe perderse de vista que las cifras de excluidos del sistema educativo siguieron siendo altas en las provincias alejadas durante la primera mitad del siglo XX e incluso, como lo señala Bjerg, en los ámbitos rurales de provincias ricas como Buenos Aires, donde la recurrencia a maestros particulares constituía una práctica sistemática. ${ }^{44} \mathrm{~A}$ pesar de ello, y contrabalanceando con peso abrumador el conjunto de capilaridades étnicas de las comunidades, la escuela pública argentina tuvo un papel decisivo en la tarea de «nacionalizar» a la enorme legión de argentinos hijos de inmigrantes. Así, por ejemplo, el censo de 1904 (uno de los relevamientos porteños que mejor contabilizó ese aspecto) puso de manifiesto que la población escolar (6 a 15 años) de la ciudad de Buenos Aires tenía un nivel muy elevado de asistencia a la escuela pública, la cual monopolizaba el $95 \%$ de la oferta educacional. ${ }^{45}$ Estas cifras testimonian la importancia de la acción del Estado, actor fundamental del proceso de integración de la población extranjera en el caso argentino, gracias al papel integrador de una escuela pública de notable expansión y cobertura, y que impulsaba un ritual patriótico de significativa capacidad de homogeneiza-

42 Otro ejemplo en tal sentido es la nota que desaconseja a un tal Monsieur Bernar su proyecto de crear un colegio francés en Buenos Aires, AMAE, 31 de diciembre de 1886, CCC, Buenos Aires, 1884-1886, Tomo 13, p. 421.

43 Así lo sugiere la exhaustiva tesis de Raquillet sobre Alfred Ébelot, personaje central de la comunidad en la década del ochenta. La autora destaca la ausencia de críticas de los líderes comunitarios franceses a la política educativa argentina, la activa militancia de Ébelot a favor de la laicización de la enseñanza en ese país y la filiación discursiva que este destacado periodista estableció entre el debate francés y el argentino. Puede hipotetizarse en consecuencia que la inspiración gala del modelo educativo argentino desarticuló las eventuales críticas de las leaderships francesas, en el caso de que hubiera existido una preocupación sobre el particular. Ver Raquillet, 2005, pp. 242-251.

44 Bjerg, 1997, pp. 251-280.

45 Para mayores detalles sobre este punto ver Otero y Pellegrino, 2003, pp. 81-112. 
ción cultural. Como lo ha mostrado Bertoni, la liturgia patriótica puesta en marcha a fines de la década de 1880 fue creciendo en las décadas siguientes hasta convertirse en hegemónica a partir de la designación en 1908 de José María Ramos Mejía al frente del Consejo Nacional de Educación. ${ }^{46}$ El papel de esa liturgia fue percibido muy claramente por los visitantes franceses del Centenario, en particular por Georges Clemenceau y Jules Huret, ${ }^{47}$ quienes dejaron vívidas descripciones de los rituales patrióticos de la educación pública del periodo (como el canto del himno, el saludo a la bandera celeste y blanca, la mitología de los héroes nacionales, las fiestas cívicas, etc.) y del alto peso de los matrimonios mixtos (en particular de hombres franceses con mujeres argentinas), que también contribuían a la «argentinización» de los hijos de esas uniones.

Un segundo factor de la debilidad del tejido educativo comunitario se vincula con la composición social de los franceses de Argentina que, como lo señalara oportunamente Bourdé, era particularmente heterogénea e incluía a estratos de muy diversa fortuna y educación. ${ }^{48}$ La presencia de cadres de las importantes empresas francesas y de personas de gran fortuna - es decir la clase alta de la comunidad que tenía nutridos contactos con la madre patria o que realizaba allí séjours más o menos prolongados y frecuentes-, favoreció el envío de los hijos a instituciones educativas de Francia, aspecto sobre el que existen múltiples ejemplos biográficos pero que resulta imposible de medir estadísticamente. ${ }^{49}$ Esta práctica debió hacer menos imperiosa la necesidad de contar con instituciones de carácter étnico, al menos para aquellos sectores medios y altos que hubieran sido, precisamente, los más capacitados para promoverlas. Lo mismo ocurría con los franceses de buena posición social que, por encontrarse en lugares aislados del país o en zonas rurales, recurrían a institutrices y educadores franceses, como lo ilustra el caso de la familia Larminat en la Patagonia. ${ }^{50}$

46 Una visión crítica de la profundización del ritual nacionalista en las escuelas a partir de la reforma Ramos Mejía — «idea de clara matriz jacobina de transformar el patriotismo en religión»— se encuentra en Escudé, 1992.

47 Clemenceau, 2002 [1911] y Huret, 1913.

48 Bourdé, 1974.

49 Las familias de modestos recursos no estaban interesadas en el envío de sus hijos a estudiar a Francia, como lo muestra el escaso éxito de algunas convocatorias promovidas por los Consulados en la década del veinte, CADN, Comité d'éducation des orphelins de guerre et fils de Français à l'étranger: Circulaire sur les pupilles de la nation, aide des consulats pour le recrutement d'enfants de français residant à l'étranger issus des milieux defavorisés, 1920, Carton 99, dossier 1539.

50 Ver De Larminat, 2004, pp. 22 y ss., que narra asimismo la decisión del autor-nieto del pionero francés- de seguir sus estudios superiores de ingeniería en la Universidad de Buenos Aires en vez de hacerlo en una institución de Francia como le había sido recomendado (pp. 41-42). 
Otro elemento central en el mismo sentido fue que la fractura de clase en la adhesión étnica a las instituciones educativas era mucho mayor que la que existía en la afiliación a las entidades asociativas. Si bien los datos disponibles son fragmentarios, todo indica que los que asistían a las escuelas étnicas eran los hijos de los sectores más integrados a la comunidad por su pertenencia laboral a empresas francesas. La Escuela Francesa de la Compañía de Ferrocarriles de Santa Fe constituye nuevamente el ejemplo más notorio de esa situación. Diversos observadores ratifican este sesgo social. Así, Serret, autor de una obra periodística y de propaganda sobre las condiciones de inmigración en Argentina, señala que entre los múltiples trabajos que realizó en su periplo rioplatense también fue docente, lo que le permitía afirmar con conocimiento de causa que los alumnos del colegio francés en el que dictaba clase eran en general los «hijos de familias de la clase alta de la colonia». ${ }^{51}$ Desde luego, la inversa de esta proposición no era necesariamente verdadera ya que muchos hijos de padres franceses de buena posición concurrían a las escuelas del Estado, como lo ilustra el caso del futuro presidente de la República Carlos Pellegrini, hijo del ingeniero francés Carlos Enrique Pellegrini, quien cursó sus estudios en el Colegio Nacional de Buenos Aires. Análogamente, las familias francesas de orígenes más modestos enviaban sus hijos principalmente a la escuela pública, que además era gratuita.

Tan importante como la fractura social fueron las expectativas de retorno de los inmigrantes - expectativas que, en buena medida, replicaban las diferencias de clase- ya que los cadres de las empresas que contaban con regresar a Francia, enviaban a sus hijos a las escuelas étnicas en mayor proporción que aquellos que pensaban quedarse definitivamente en la Argentina. Ese fue, por ejemplo, el caso del Colegio Francés de Buenos Aires, frecuentado sobre todo por «hijos de franceses o de extranjeros establecidos temporariamente y en menor grado por hijos de franceses establecidos definitivamente, en fin por algunos jóvenes argentinos de buena familia». ${ }^{52}$

En la misma clave argumentativa, los proyectos de creación de un liceo francés, necesidad señalada desde principios del siglo XX, resultan ilustrativos del dilema planteado por las fracturas de la estructura social, tanto argentina como de la comunidad. En un pormenorizado proyecto de

51 Serret, 1915, p. 70.

52 AMAE, Note sur la colonie, p. 222. 
1910, su autor, Monsieur Morel, consideraba que la iniciativa era factible pero que, dados los costos que supondría, el liceo sólo podría captar a los hijos de las familias «ricas e influyentes» de la clase alta argentina y no a la mayoría de los hijos de la colonia francesa o de origen francés, «generalmente de condición media». Siguiendo el modelo de las escuelas alemanas de Buenos Aires, Morel consideraba que sería mejor orientar el liceo a la preservación cultural de los hijos de la colonia, para luego lamentar que si bien los «precios cerrarán la puerta del liceo francés, con pocas excepciones, a los hijos de las familias francesas o de origen francés», la iniciativa sería de todos modos oportuna para desarrollar la influencia francesa en la Argentina. En cualquiera de los dos casos «el liceo debería tener en cuenta los programas argentinos y completarlos». ${ }^{53} \mathrm{La}$ posibilidad de que el colegio se orientara de preferencia a la alta burguesía argentina era ilustrada asimismo por una nota del diario La Nación del 12 de octubre de 1911, en la que se mencionaba que sus patrocinadores no eran franceses en su gran mayoría sino notables argentinos como Carlos Octavio Bunge, el ex ministro de Finanzas Piñero, Rodolfo Rivarola y Juan Agustín García, entre otros. Un nuevo proyecto de 1921 preveía la creación de un liceo franco-argentino basado en el modelo del de Sao Paulo en Brasil, es decir con administración franco-argentina, con capitales de los dos países y con subvenciones de los dos gobiernos. ${ }^{54} \mathrm{~A}$ pesar de estos y otros proyectos, el Liceo Franco-Argentino «Jean Mermoz» de Buenos Aires no fue creado hasta 1964, fuera de nuestro periodo de observación, siguiendo el modelo del de Sao Paulo, e inaugurado con la presencia del general Charles de Gaulle.

Otro factor influyente en la menor importancia de las escuelas étnicas debió vincularse con rasgos propios de la experiencia premigratoria de los

53 CADN, Rapport au Ministre de France E. Thiebaut à Buenos Aires et au MAE, Buenos Aires, 19 de enero de 1910, «Project de création d'un lycée français à Buenos Aires, 1909-1911, Carton 83. Para esos años, Clemenceau, 2002 [1911], p. 59, señalaba que una de las preocupaciones principales del polifacético Paul Groussac era la de crear un liceo francés en la capital con el apoyo de ambos gobiernos.

54 AMAE, Service des Oeuvres Française à l'Étranger, 25 de junio 1920, Carpeta Amérique, 1918-1940, Argentine (14), Propagande, 1914-1921, p. 133. Casi al mismo tiempo, el Informe de René Viviani de 1921 se oponía a la creación de un liceo francés argumentando que primero debería evaluarse la experiencia del liceo de Brasil, que sería una empresa extremadamente costosa, que sólo serviría para «educar a los hijos de franceses y a algunos argentinos que permanecen fijados en su país», y que los profesores franceses terminarían por ser «absorbidos por el medio». En su opinión, la fórmula más eficaz y menos costosa consistía en favorecer los intercambios universitarios entre ambos países. Véase AMAE, Rapport Viviani, Carpeta Amérique, 1918-1940, Argentine (14), Propagande, 1914-1921. 
migrantes franceses, cuyo nivel de alfabetización era muy superior al de italianos y españoles, aunque menor que el de ingleses y alemanes. El paso por la escuela pública francesa, sobre todo a partir de las decisivas reformas laicas y universalistas introducidas por la Tercera República, debió hacer que la necesidad de nacionalizar a los inmigrantes en la cultura de origen fuera para las elites comunitarias francesas mucho menos imperiosa que para las italianas. La tardía unificación de Italia, el alto grado de analfabetismo de los emigrantes y la necesidad de crear en ellos un sentimiento nacional italiano fue una preocupación central de ese joven Estado y de las leaderships de ese origen de la Argentina, sobre todo a partir de la pérdida de poder —en la década de 1880 — de los sectores republicanos y anticlericales de inspiración mazziniana.

\section{Conclusiones}

Llegados a este punto, y dejando de lado las conclusiones parciales de cada apartado, pueden esbozarse algunas conclusiones mayores. En relación al problema de la integración de los inmigrantes europeos, el análisis de los núcleos étnicos de las escuelas sugiere la imposibilidad de zanjar el debate a partir de los términos dicotómicos y simplistas que, en el pasado, opusieron a los partidarios del Pluralismo Cultural y del Crisol de Razas. En tal sentido, los registros temporales y espaciales reconstruidos sugieren claramente la existencia de momentos y de espacios más típicamente «pluralistas» y momentos y espacios más cercanos al Crisol.

Visto en términos temporales, el auge de las escuelas étnicas se situó entre 1880 y la década previa al Centenario. A partir de la primera posguerra y, sobre todo, de la crisis de 1930, las dificultades financieras de las instituciones y la creciente ingerencia y expansión del sistema educativo público crearon condiciones más difíciles para su desarrollo. El debilitamiento de las escuelas laicas fue más precoz que el de las escuelas congregacionales por la diferente capacidad de los actores involucrados (esfuerzos privados en el primer caso, instituciones bien organizadas y de carácter internacional en el segundo), por el tipo de público al que atendían (una comunidad migratoria en retroceso y progresivamente envejecida versus un público amplio y plurinacional) y por el tipo de discursos que fomentaban, favorecido - en el caso de las escuelas religiosas - por su carácter universalista y, a partir de los años treinta del siglo XX, por la recuperación del 
catolicismo en la Argentina. Con todo, su carácter étnico demanda, al igual que muchos otros aspectos, nuevas investigaciones.

El análisis espacial, por su parte, confirma que las condiciones de posibilidad del pluralismo eran mayores en las grandes ciudades como Tucumán, Córdoba, Rosario y, sobre todo, la capital del país, hallazgo que resulta coherente con otros indicadores de la integración migratoria como la exogamia, la afiliación al movimiento asociativo, la segregación espacial y la persistencia idiomática.

Las elevadas proporciones de hijos de inmigrantes fuera del núcleo étnico alertan asimismo sobre la importancia decisiva que tuvieron otras formas alternativas de formación de identidades -en este caso, las escuelas públicas, pero también las instituciones religiosas- que han recibido poca atención por parte del Pluralismo. La escasa presencia de hijos de inmigrantes en las escuelas francesas limitó así la función de reproducción cultural intergeneracional de esos espacios y facilitó la integración a la sociedad argentina, como lo puso de manifiesto el rechazo de la segunda generación a la movilización militar durante la Gran Guerra.

La comunidad francesa de la Argentina, al igual que otros grupos migratorios, desplegó un esfuerzo educacional considerable que, a pesar de sus logros, no alcanzó sin embargo el desarrollo que tuvo su vigoroso movimiento asociativo. Ello fue así por unas razones que se vincularon tanto con las condiciones premigratorias - el alto grado, en comparación con otros colectivos, de alfabetización y nacionalización de sus emigrantes - como postmigratorias. Entre estas últimas se destacó, a partir de la década de 1880 , la puesta en marcha de un modelo republicano de integración de inspiración francesa que centró sus esfuerzos en la creación de un sistema público de enseñanza obligatoria al servicio de la construcción de la nacionalidad argentina. El desarrollo de este modelo, tanto en el plano ideológico como en el legal y material, redujo considerablemente el margen de acción y la utilidad misma de las escuelas étnicas, y contribuyó a desarticular las eventuales críticas de las leaderships francesas de matriz republicana.

Igualmente relevantes fueron la fractura de clase existente en el grupo migratorio y las diferentes expectativas de retorno, factores que confinaron las escuelas étnicas al reducido ámbito de los sectores sociales altos de las grandes ciudades o de lugares más cercanos al modelo de enclave étnico como la colonia aveyronesa de Pigüé. La permeabilidad del Estado en la incorporación de educadores franceses durante buena parte del perio- 
do analizado posibilitó asimismo su ingreso a la educación pública argentina, desalentando su inserción en la educación étnica.

Por otra parte, los planes franceses de expansión en Latinoamérica puestos en marcha tras la Gran Guerra dieron prioridad a la difusión de la cultura francesa, en particular el idioma, entre la población argentina en general. Este objetivo, al igual que su diagnóstico de base - la reducción del tamaño y la pérdida de dinamismo de las comunidades francesas allí instaladas y el avance de la influencia de otros países, en particular Alemania y Estados Unidos-, alteró las prioridades de Francia y reorientó los esfuerzos hacia la propaganda, en detrimento de las instituciones educativas comunitarias, si bien éstas nunca habían contado con un apoyo demasiado significativo.

Por último, aunque la reconstrucción de los núcleos étnicos presenta también problemas heurísticos considerables, constituye una vía alternativa para el estudio de las escuelas étnicas, sobre todo cuando, como en el caso del colectivo francés, no se dispone de las fuentes necesarias para acceder al funcionamiento interno de esas instituciones.

Recibido el 04 de mayo de 2010 Aceptado el 08 de noviembre de 2010

\section{Bibliografía}

Andreu, Jean ; Bennassar, Bartolome; y Gaignard, Roman: Les Aveyronnais dans La Pampa. Fondation, développement et vie de la colonie aveyronnaise de Pigüé, Argentine, 1884-1974, Toulouse, Université de Toulouse-le-Mirail, Privat, 1977.

Auza, Néstor Tomás (comp.): Iglesia e inmigración en la Argentina, Buenos Aires, CEMLA, 2005.

Baubérot, Jean: Histoire de la lä̈cité française, Paris, PUF, 2000.

Bertoni, Lilia Ana: Patriotas, cosmopolitas y nacionalistas. La construcción de la nacionalidad argentina a fines del siglo XIX, Buenos Aires, FCE, 2001.

Bjerg, María: «Educación y etnicidad en una perspectiva comparada. Los inmigrantes daneses en la pradera y en la pampa, 1860-1930», Estudios Migratorios Latinoamericanos, 36, Buenos Aires, agosto de 1997, 251-280.

Borea, Domingo: «La mutualidad y el cooperativismo en la República Argentina por el Dr. Domingo Borea», en República Argentina: Tercer Censo Nacional, Buenos Aires, Talleres Gráficos de L.J. Rosso y Cía, Tomo X, 1917, 83-347. 
Bourdé, Guy: Buenos Aires: Urbanización e inmigración, Buenos Aires, Editorial Huemul, 1974.

Bruno, Paula: Paul Groussac. Un estratega intelectual, Buenos Aires, FCE/UDESA, 2005.

Bruno, «La vida letrada porteña entre 1860 y el fin de siglo. Coordenadas para un mapa de la elite intelectual», Anuario IEHS, 24, Tandil, 2009, 339-368.

Clemenceau, Georges: La Argentina del Centenario, Quilmes, UNQui, 2002 [1911].

Daireaux, Émile: République Argentine. La vie sociale et la vie légale des étrangers, París, Hachette, 1889.

De Larminat, Miguel: Un pionero de la Patagonia, Buenos Aires, El Ateneo, 2004.

Croix-Riche Chanet, Charles R.: Franceses en el Río de la Plata y el Atlántico Sur, 1526-1876, Buenos Aires, Mega Libros, 2004.

Devoto, Fernando y Otero, Hernán: «Veinte años después. Una lectura sobre el Crisol de Razas, el Pluralismo Cultural y la Historia Nacional en la historiografía argentina», Estudios Migratorios Latinoamericanos, 50, Buenos Aires, 2003, 181-227.

Di Liscia, María Herminia y LaSalle, Ana María (eds.): «Esta fue mi vida. No se la deseo a ninguna»- A propósito de la 'Narración de mi vida, 1884-1937' de Anaís Vialá, Santa Rosa, Universidad Nacional de La Pampa, 2002.

Duclert, Vincent y Prochasson, Christophe (dirs.): Dictionnaire critique de la République, Paris, Flammarion, 2007.

Dussaut, Alejandro: La colonia francesa en el Río de la Plata, Buenos Aires, Edición del Club Francés, 1966.

Escudé, Carlos: «La generación de una cultura autoritaria a través de los contenidos de la educación durante el siglo XX», Índice, 5, Buenos Aires, abril de 1992, 17-74.

Favero, Luigi: «Las escuelas de las sociedades italianas en la Argentina», en Devoto, Fernando y Rosoli, Gianfausto (comps.): La Inmigración Italiana en la Argentina, Buenos Aires, Editorial Biblos, 1985, 165-207.

Frenette, Yves: «Explorations. Les Français au Canada, 1760-1930», Colloque International «Les migrants français aux Amériques, 17e-20e siècles», Paris, CENA-EHESS, 12-14 diciembre de 2002.

Frid de Silberstein, Carina: «Mutualismo y educación en Rosario: las escuelas de la Unione e Benevolenza y de la Sociedad Garibaldi (1874-1911)», Estudios Migratorios Latinoamericanos, 1, Buenos Aires, diciembre de 1985, 77-97.

Frid de Silberstein, « Las opciones educativas de la comunidad italiana en Rosario: Las escuelas mutualistas y el colegio Salesiano (1880-1920)», en Devoto, Fernando y Míguez, Eduardo (comps.): Asociacionismo, trabajo e identidad étnica. Los italianos en América Latina en una perspectiva comparada, Buenos Aires, CEMLA, CSER, IEHS, 1992, 101-114. 
González OP, Fr. Rubén: «Iglesia e inmigración en la Argentina, 1810-1914», en AA.VV.: La inmigración en la Argentina, Tucumán, Facultad de Filosofía y Letras, Universidad Nacional de Tucumán, 1979, 89-122.

Guionet, Héctor: «2 de julio de 1857: voces francesas en el monte entrerriano», en Ochoa de Eguileor, Jorge (ed.): Inmigración francesa en Argentina, Buenos Aires, Total Austral, 2005, 131-137.

Huret, Jules: En Argentine, de la Plata à la cordillère des Andes, Paris, Editions Fasquelle, 1913.

Institut National de la Statistique et des Etudes Économiques: Français et institutions françaises à l'étranger en 1950. Résultats de l'enquête du Ministère des Affaires Étrangères en date du 31 décembre 1950, Paris, Imprimerie Nationale, 1955.

Lassalle, Ana María; Mayol Lassalle, Mercedes; y Colombato, Julio A.: El largo viaje de Mme. Soulié. Protagonismo de una educadora francesa en Santa Rosa, 1914-1924, Santa Rosa, Universidad Nacional de La Pampa, 1998.

Lhande, Pierre: L'émigration basque. Histoire, Economie, Psychologie, Donostia, Elkar, 1984 [1910].

Otero, Hernán: «La inmigración francesa en la Argentina, 1850-1914. Formas de integración desde una perspectiva regional», en Ochoa de Eguileor (comp.): Inmigración francesa en Argentina, 2005, 107-115.

Otero, La guerra en la sangre. Los franco-argentinos ante la Primera Guerra Mundial, Buenos Aires, Sudamericana, 2009.

Otero, «El asociacionismo étnico francés en la Argentina. Una perspectiva secular», Estudios Interdisciplinarios de América Latina y el Caribe, Universidad de Tel Aviv, en prensa.

Otero, Hernán y Pellegrino, Adela: «Sharing the City: Residence Patterns and Immigrant Integration in Buenos Aires and Montevideo», en Baily, Samuel y Míguez, Eduardo (eds.): Mass Migration to Modern Latin America, Wilmington, Jaguar Books, 2003, 81-112.

Páez de la Torre, Carlos: «Los franceses en Tucumán», en AA.VV.: La inmigración en la Argentina, 1979, 41-44.

Papillaud, Henri: Chroniques Argentines, Buenos Aires, Librería C.M. Joly, 1909.

Pelosi, Hebe Carmen: Argentinos en Francia. Franceses en Argentina. Una biografía colectiva, Buenos Aires, Ediciones Ciudad Argentina, 1999.

Puiggrós, Adriana (dir.): Historia de la educación en la Argentina, Buenos Aires, Editorial Galerna, 1990-1991, 2 tomos.

Quintal, Claire (dir.): Les franco-américains et leurs institutions scolaires, Worcester, Massachusetts, Institut Français, 1990.

Raquillet, Pauline: Alfred Ébelot ou le parcours migratoire d'un Français dans l'Argentine du XIXème siècle, Thèse de Doctorat, Université de Paris VII, 2005. 